\title{
Evidence for Neurotoxicity from Quinoline Antimalaria Drugs: Four Personal Accounts
}

\author{
Ashley M. Croft ${ }^{*}$, Anthony R. Mawson ${ }^{2}$ \\ ${ }^{1}$ School of Pharmacy and Biomedical Science, University of Portsmouth, Portsmouth, UK \\ ${ }^{2}$ School of Public Health (Initiative), Jackson State University, Jackson, MS, USA \\ Email: ^Ashley.Croft@myport.ac.uk
}

How to cite this paper: Croft, A.M. and Mawson, A.R. (2017) Evidence for Neurotoxicity from Quinoline Antimalaria Drugs: Four Personal Accounts. Open Journal of Animal Sciences, 7, 45-55.

http://dx.doi.org/10.4236/ojas.2017.71005

Received: December 9, 2016

Accepted: January 9, 2017

Published: January 12, 2017

Copyright $\odot 2017$ by authors and Scientific Research Publishing Inc. This work is licensed under the Creative Commons Attribution International License (CC BY 4.0).

http://creativecommons.org/licenses/by/4.0/ cc) (i)

Open Access

\begin{abstract}
Background: The adverse effects of mefloquine and other quinoline antimalaria drugs can be severe and long-lasting. We believe that the trigger for these effects may be drug-induced hepatocellular damage that causes, firstly, a spillage of retinoids into the circulation (and hence a direct toxic effect on the brain and other target organs), and secondly, disruption of the liver-thyroid axis (and hence a pattern of specific bipolar symptoms such as is often seen in thyroid disease). Methods: We sought recently-published lay accounts of adverse effects in users of quinoline antimalaria drugs, to test these lay descriptions against our hypothesis on the likely pathogenesis of these effects. Results: We found six lay accounts that described four different experiences of adverse effects arising from the prophylactic use of quinoline antimalaria drugs. All four travellers were healthy, at the start of travel. Two of the travellers experienced severe psychoses, and one had a mild psychosis. The fourth traveller, a serving US soldier, killed 16 unarmed Afghan civilians. Analysis of these accounts shows that, based on our hypothesis, all four travellers had at least one risk factor (most commonly, concurrent alcohol use), for developing a severe reaction to their quinoline antimalaria drug. Our hypothesis therefore predicted a severe adverse drug reaction in each of these four travellers. We also identified a hitherto unrecognized risk factor for developing a severe reaction to quinoline antimalaria drugs-namely, the concurrent use of anabolic steroids. Conclusions: Lay accounts of drug adverse effects can help initiate or further develop medical hypotheses of their pathogenesis. We advise that the quinoline class of antimalaria drugs should be prescribed cautiously, and that mefloquine should not now be prescribed for malaria prophylaxis, under any circumstances whatsoever. Where persistent adverse effects have resulted from the historical use of quinoline antimalaria drugs, we propose a five-point management strategy that we believe will in most cases cause symptoms to abate rapidly: 1) stop taking the quinoline drug; 2) stop alcohol, and stop all other liver-damaging drugs, including anabolic steroids, hormonal contraception, hormone replacement therapy, recreational drugs, antidepressants, anxiolytics and hypnotics; 3 ) maintain good hydration, using non-fluoridated drinking water; 4) temporarily eliminate die-
\end{abstract}


tary vitamin A; as an additional and optional therapeutic measure, 5) lower the concentration of circulating retinoids through phlebotomy, plasmapheresis or hirudotherapy.

\section{Keywords}

Afghanistan, Bales, Lariam, Malaria, Mefloquine, Pibloktoq

\section{Introduction}

Croft and Herxheimer in 2002 [1] and Mawson in 2013 [2] independently advanced two distinct but complementary hypotheses to explain the neurotoxic and other adverse effects associated with mefloquine, a quinoline antimalaria drug. Mefloquine (i.e. Lariam, a potent, long-acting blood schizonticide manufactured by F. Hoffmann-LaRoche $\mathrm{AG}$ ) is chemically related to other quinoline derivatives such as amodiaquine and chloroquine [3]; hence the two hypotheses might reasonably apply to these related antimalaria compounds also.

\subsection{Croft-Herxheimer (Liver-Thyroid) Hypothesis}

Many of the adverse effects of mefloquine (and, by analogy, of other quinolineantimalaria agents also) are a post-hepatic syndrome caused by primary liver damage [1]. The liver plays a key part in the metabolism of thyroid hormones (Weetman, 2010). Mefloquine-induced liver damage disrupts the exquisitely delicate physiological relationship between the liver and the thyroid gland ("the liver-thyroid axis"). Thyroid hormone imbalance then occurs, either as excess or as deficiency of circulating thyroid hormone. Symptomatic thyroid disturbance may result. Thyroid disease is typically bipolar in its mode of presentation (i.e. it presents as weight loss or weight gain, preference for a cool climate or a warm climate, nervousness or lethargy, diarrhea or constipation, etc.) [4], and this pattern of physiological opposites features commonly in published case reports of mefloquine adverse effects. Previous liver or thyroid disease is a risk factor for developing adverse effects from mefloquine. The mefloquine syndrome presents variously as headache (suggesting a direct toxic effect on the brain, superimposed on disruption of the liver-thyroid axis), gastrointestinal disturbances, nervousness, fatigue, disorders of sleep, mood, memory and concentration, and occasionally frank psychosis [1] [5].

Symptoms of mefloquine toxicity tend to abate spontaneously once the drug is discontinued, provided that concurrent chemical insults to the liver are also discontinued, or corrected. These concurrent chemical insults may include:

1) Alcohol,

2) Dehydration,

3) An oral contraceptive pill, or hormonal replacement therapy,

4) Recreational drugs,

5) Other liver-damaging co-medications.

Co-medications in the last of the above sub-categories likely to be especially hazardous in mefloquine users are, firstly, those medicines that cause hepatocellular injury and 
also are thyroid hormone antagonists (e.g. amiodarone, benzodiazepine, calcium channel blockers, phenytoin); and secondly, other quinine analogues taken concurrently with mefloquine, such as fluoroquinolone antibiotics [1]. It should not be necessary to treat mefloquine adverse effects through specific drug therapy; administering further drugs could in fact make mefloquine's adverse effects worse, or cause them to become permanent [1].

In those commonly-reported cases where the adverse effects of mefloquine persist for months, or years, the explanation often lies in the fact that after stopping mefloquine the mefloquine-damaged individual continues to take alcohol, or liver-damaging prescription drugs such as antidepressants, or (in the case of women) hormonal contraception [1].

\subsection{Mawson (Endogenous Hypervitaminosis A) Hypothesis}

Vitamin A is stored mainly in the liver, in potentially poisonous concentrations [2]. A condition known as pibloktoq (or "Arctic hysteria") has been described in Inuit people and attributed to hypervitaminosis A after their gorging on vitamin A-rich polar bear or seal liver [6]. Pibloktoq manifests as irrational and sometimes violent acts, followed by amnesia for the event [7]. It affects dogs, as well as humans [6].

The adverse effects of mefloquine (and, presumably, of other quinoline antimalaria drugs also) may result from drug-induced liver damage that provokes an endogenous syndrome analogous to hypervitaminosis $\mathrm{A}$, and that is characterized by the spillage of toxic retinoid compounds into the circulation. At a cellular level the mechanisms contributing to this physiological harm may include:

1) Mefloquine-induced dehydrogenase inhibition,

2) The accumulation of retinoids in the liver,

3) Retinoid-induced hepatocellular damage,

4) The spillage of stored retinoids into the circulation,

5) The transport of retinoid compounds to the gut and brain, in toxic concentrations.

This same hypothesis plausibly explains Stevens-Johnson syndrome (SJS) and toxic epidermal necrolysis (TEN); these should be considered as overlapping manifestations on a spectrum of acute drug-induced conditions associated with severe blistering, skin peeling, and multi-organ damage [8]. Of interest, SJS was attributed to mefloquine, early in the drug's prescribing history [9]. Likewise, TEN has been attributed to chloroquine, in a user who concurrently took pyrimethamine plus dapsone (i.e. Maloprim), aspirin and propranolol [10].

As with the Croft-Herxheimer hypothesis, Mawson's hypothesis suggests that simply stopping mefloquine will usually suffice to bring about a swift remission of unwanted drug effects, where these have occurred. Symptom worsening could also potentially be arrested by lowering the concentration of circulating retinoids through phlebotomy or plasmapheresis, or else through pharmacological measures to limit the further expression of these substances [8].

\subsection{The Current State of Knowledge}

The Croft-Herxheimer-Mawson hypothesis has not been tested formally-for example, in a case-control study incorporating both detailed symptom ascertainment, and thy- 
roid and liver biochemistry (including retinoid profiles) in a population of quinoline antimalaria drug users. Hence, the hypothesis remains speculative. If valid, the model may explain the pathogenesis of other disease states, such as primary biliary cirrhosis [11] and dengue haemorrhagic fever [12].

Notwithstanding the above, adverse effects from the quinoline class of antimalaria drugs continue to be commonly reported, in both the scientific [13] [14] [15] and lay literature. We undertook to explore the latter resource for evidence that might serve to support (or alternatively to discredit) our as yet untested hypothesis on the pathogenesis of the neurotoxic and other adverse effects associated with quinoline antimalaria drugs.

\section{Methods}

During 2013-2016 we non-systematically searched the published lay literature in different formats (books, newspapers, magazines) for accounts describing adverse effects from quinoline antimalaria drugs, in lay users of these drugs. We selected and analyzed those reports with sufficient detail to enable us to judge the apparent concordance with or divergence from our pre-existing hypotheses of adverse event causation related to this class of drugs. We identified these lay accounts serendipitously; none of the accounts was or is now indexed on any standard scientific bibliographical database, such as Pubmed or Embase.

\section{Results}

\section{Case Reports}

We identified four published experiences of adverse effects from quinoline antimalaria drugs that were reported between 2013-2016 in six separate lay accounts, in sufficient detail for us to undertake a comparative analysis of their content.

One report (Case Study One) [16] described mefloquine use in a 29-year old male traveller; a second report (Case Study Two) [17] [18] described either amodiaquine or chloroquine use in a 43-year old male traveller; a third report (Case Study Three) [19] [20] described probable mefloquine use in a 38-year old male traveller, against a probable background of previous, prolonged chloroquine use; a fourth report (Case Study Four) [21] described mefloquine use in a young male writer. All four travellers were ostensibly healthy, prior to their index experience of drug-induced adverse effects.

All of the six lay accounts we identified, representing four different experiences of quinoline drug-related harm, were written for a predominantly lay readership. None of the accounts included any reference to or apparent knowledge of our respective hypotheses [1] [2] [8] [11] [12].

The general characteristics of the four case studies are summarized at Table 1.

A comparative analysis of the content of the four case studies is at Table 2.

\section{Discussion}

We analyzed four recently-published case reports drawn from the non-specialist lay literature, describing the adverse effects of quinoline antimalaria drugs. We sought evidence that could illuminate our untested hypotheses on how these adverse effects are 
Table 1. General characteristics of four published lay accounts of adverse effects from quinoline antimalaria drugs.

\begin{tabular}{ccccc}
\hline & $\begin{array}{c}\text { Nationality } \\
\text { [occupation }] \\
\text { of subject }\end{array}$ & $\begin{array}{c}\text { Context of the } \\
\text { account }\end{array}$ & $\begin{array}{c}\text { Quinoline antimalaria } \\
\text { drug used }\end{array}$ & $\begin{array}{c}\text { Main drug-related } \\
\text { symptoms } \\
\text { reported }\end{array}$ \\
\hline $\begin{array}{c}\text { Case Study } \\
\text { One [12] }\end{array}$ & US [writer] & Autobiography & Mefloquine & Amnesia \\
$\begin{array}{c}\text { Case Study } \\
\text { Two [9] [18] }\end{array}$ & $\begin{array}{c}\text { British } \\
\text { [comedian] }\end{array}$ & $\begin{array}{c}\text { Autobiography, } \\
\text { newspaper } \\
\text { reports }\end{array}$ & $\begin{array}{c}\text { Amodiaquine? } \\
\text { Chloroquine? }\end{array}$ & Paranoia \\
$\begin{array}{c}\text { Case Study } \\
\text { Three [2] } \\
\text { [20] }\end{array}$ & US [soldier] & $\begin{array}{c}\text { Newspaper } \\
\text { reports }\end{array}$ & $\begin{array}{c}\text { Probable mefloquine use } \\
\text { Probable prior } \\
\text { chloroquine use }\end{array}$ & $\begin{array}{c}\text { Paranoia, extreme } \\
\text { violence (multiple } \\
\text { homicide) }\end{array}$ \\
$\begin{array}{c}\text { Case Study } \\
\text { Four [2] }\end{array}$ & $\begin{array}{c}\text { British } \\
\text { [comedian] }\end{array}$ & Magazine article & Mefloquine & $\begin{array}{c}\text { Mild psychosis, } \\
\text { sleep disturbance }\end{array}$ \\
\hline
\end{tabular}

generated, and on how they might be mitigated, or treated. To our knowledge, this exercise has not been performed previously, even though it has been accepted for some years that clinical case studies, including those normally regarded as purely anecdotal [22] [23] [24], can provide useful information for generating or refining scientific hypotheses, in the absence of high-level evidence from randomized controlled trials or from systematic reviews of trials.

The case studies show that, in addition to the users having each taken quinoline antimalaria drugs, a number of additional risk factors (as predicted by the Croft-Herxheimer-Mawson model) were present in each case. This supports our hypothesis on the pathogenesis of adverse effects with this class of drugs, since we would have predicted a priori that the four subjects would each have been at high risk of a severe adverse reaction from their prescribed antimalaria medication.

The fact that a prolonged period of drug-related harm was reported in Case Study One, Two and Four (the outcome in Case Study Three is unknown) was also foreseeable. Our hypothesis would have predicted a quicker and more complete recovery from the unwanted effects of the quinoline drugs taken, had psychotropic drugs not been used (as they plainly were, at least in Case Study One and Two) in an attempt to treat those effects.

Case Study Three is of special interest because of the extreme consequences (the self-confessed murder of 16 Afghan civilians) that were attributed in the published lay accounts to the subject's use of a quinoline antimalaria drug. Following a newspaper Freedom of Information request to the FDA, there now exists in the public domain [25] a redacted Adverse Event Report that plainly relates to this user, and which indicates that he was taking mefloquine at the time of his homicidal acts (Figure 1). In the years immediately preceding 2012 it is highly likely that this military user had been taking chloroquine, as malaria prophylaxis during three successive deployments to Iraq. This will have pre-sensitized him to the effects of mefloquine, we believe. This individual's concurrent use of anabolic steroids, a class of drugs metabolized in the liver and known 
Table 2. Detailed analysis of three published lay accounts of adverse effects from quinoline antimalaria drugs.

\begin{tabular}{|c|c|c|c|c|}
\hline & $\begin{array}{l}\text { Date when } \\
\text { adverse drug } \\
\text { reactions } \\
\text { occurred }\end{array}$ & Risk factors present?* & $\begin{array}{c}\text { Treatment } \\
\text { administered }\end{array}$ & $\begin{array}{l}\text { Symptom } \\
\text { duration }\end{array}$ \\
\hline $\begin{array}{c}\text { Case } \\
\text { Study } \\
\text { One } \\
{[16]}\end{array}$ & October 2002 & $\begin{array}{l}\text { 1. Alcohol. Yes. Narrative account } \\
\text { declares regular use of beer. } \\
\text { 2. Dehydration. Likely. Symptoms } \\
\text { emerged after some months' residence } \\
\text { in India. } \\
\text { 3. Contraceptive pill/hormonal } \\
\text { therapy. No. } \\
\text { 4. Recreational drugs. Yes. Prior drug } \\
\text { misuse declared. } \\
\text { 5. Other liver-damaging agents. None } \\
\text { described. } \\
\text { 6. Other risk factors. None described. }\end{array}$ & $\begin{array}{l}\text { Hospitalisation } \\
\quad(3 \text { days) } \\
\text { Sedative drugs } \\
\text { administered }\end{array}$ & $\begin{array}{c}>11 \text { years } \\
\text { (gradually } \\
\text { abating) }\end{array}$ \\
\hline $\begin{array}{c}\text { Case } \\
\text { Study } \\
\text { Two } \\
{[17]} \\
{[18]}\end{array}$ & December 1989 & $\begin{array}{l}\text { 1. Alcohol. Yes. Narrative account } \\
\text { describes regular use of beer, brandy, } \\
\text { champagne, vodka, whisky. } \\
\text { 2. Dehydration. Likely. Symptoms } \\
\text { worsened after long flight to Kenya. } \\
\text { 3. Contraceptive pill/hormonal } \\
\text { therapy. No. } \\
\text { 4. Recreational drugs. Yes. Narrative } \\
\text { account describes prior use of LSD. } \\
\text { 5. Other liver-damaging agents. Yes. } \\
\text { Previous use of morphine. } \\
\text { 6. Other risk factors. Yes. Prior } \\
\text { hepatitis A. Also, following the onset of } \\
\text { adverse drug effects, the } \\
\text { quinoline antimalaria drug (either } \\
\text { amodiaquine or chloroquine) was } \\
\text { accidentally administered in overdose } \\
\text { for several days, while the user was } \\
\text { hosnitalized }\end{array}$ & $\begin{array}{l}\text { Hospitalisation } \\
(2 \text { months) } \\
\text { Antipsychotic } \\
\text { medication } \\
\text { (chlorpromazine } \\
\text { hydrochloride) } \\
\text { administered }\end{array}$ & $\begin{array}{c}>2 \\
\text { months } \\
\text { (gradually } \\
\text { abating) }\end{array}$ \\
\hline $\begin{array}{c}\text { Case } \\
\text { Study } \\
\text { Three } \\
{[19]} \\
{[20]}\end{array}$ & March 2012 & $\begin{array}{l}\text { 1. Alcohol. Yes. Narrative account } \\
\text { describes concurrent use of whisky } \\
\text { (Jack Daniels). } \\
\text { 2. Dehydration. Likely. Symptoms } \\
\text { emerged acutely after some months' } \\
\text { residence in Afghanistan. } \\
\text { 3. Contraceptive pill/hormonal } \\
\text { therapy. No (but see } 5 \text { below). } \\
\text { 4. Recreational drugs. No. } \\
\text { 5. Other liver-damaging agents. Yes. } \\
\text { Concurrent use of a synthetic anabolic } \\
\text { steroid (stanozolol), for muscle } \\
\text { building. } \\
\text { 6. Other risk factors. Yes. There was } \\
\text { probable prior use of chloroquine in } \\
\text { Iraq, over a period of, potentially, } \\
\text { several years. In addition, traumatic } \\
\text { brain injury (a putative risk factor) } \\
\text { had been experienced in the past. }\end{array}$ & Unknown & Unknown \\
\hline
\end{tabular}


Continued

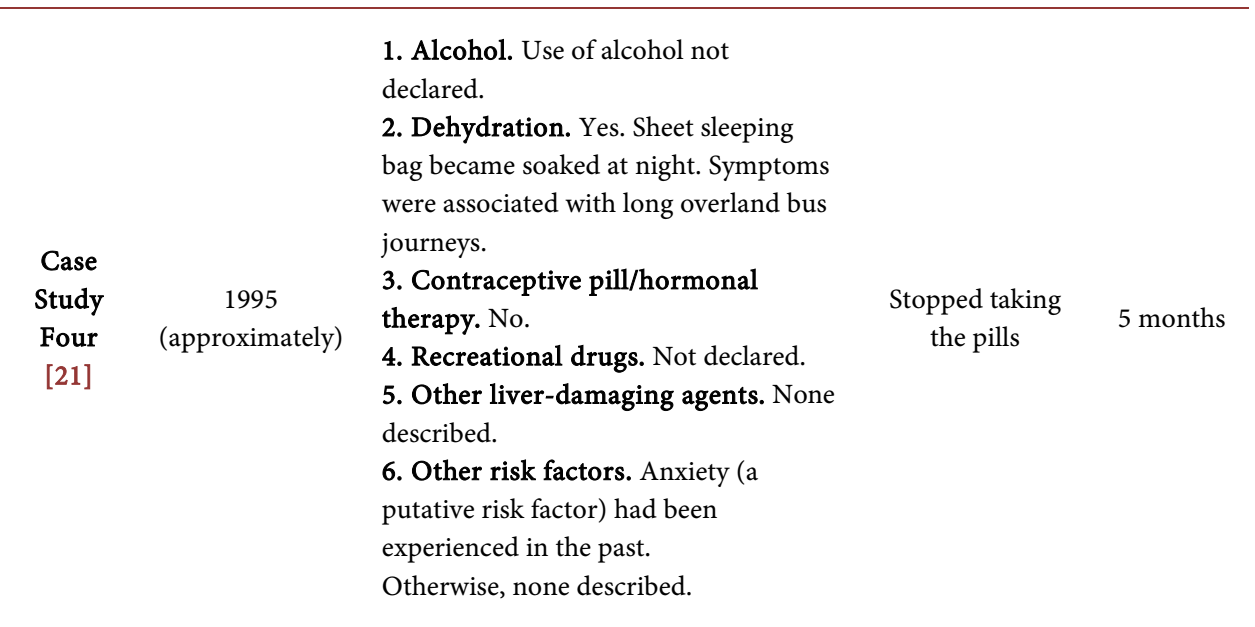

*The risk factors for developing severe and/or prolonged adverse effects from antimalaria quinoline drugs are those proposed in our hypothesis papers [1] [2] [8] [11] [12]; not all the proposed risk factors are widely accepted, as yet.

\section{FDA - Adverse Event Reporting System (FAERS) FOIA Case Report Information}

\section{Case ID: 8504150}

Case Information:
Case Type: EXPEDITED (15- eSub: Y HP: Y Country: USA Outcomes: OT
DAY)
(A)NDABLA: 019591 I

FDA Rcvd Date: 11-Apr-2012 Mfr Revd Date: 29-Mar-2012 Mfr Control \#: US-ROCHE-1054403

Patient Information:

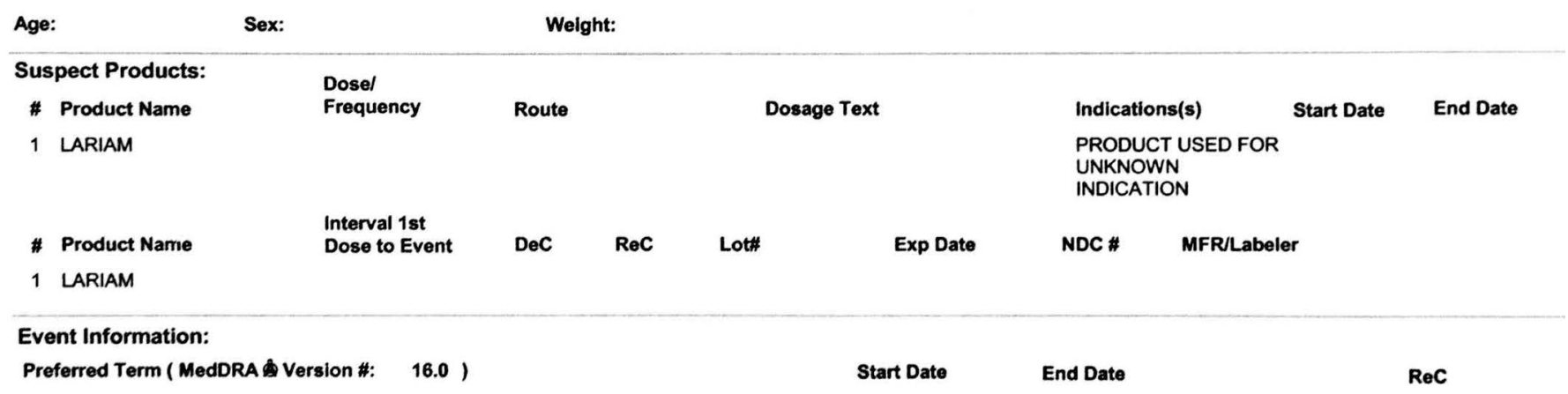

HOMICIDE

\section{Event/Problem Narrative:}

Initial Information for this Spontaneous case, AER number 1054403, was received on 29/Mar/2012 from a Pharmacist and concerns a patient of unknown demographics who was treated with Mefloquine Hydrochloride (Lariam) for an unknown indication. Medical history included TBI (Traumatic brain injury). No concurrent illnesses were reported. No concomitant medications or past drugs were reported. On an unknown date, the patient started Mefloquine Hydrochloride (dose, form and frequency not reported). On an unknown date the patient who was a soldier in the US Army developed homicidal behavior and led to Homicide killing 17 Afghanis. It was reported that this patient was administered Mefloquine in direct contradiction to US military rules that Mefloquine should not be given to soldiers who had suffered TBI (Traumatic brain injury) due to its propensity to cross blood brain barriers inciting psychotic, homicidal or suicidal behavior. The outcome of Homicide was not Reported. There was insufficient information regarding the therapy ongoing status of Mefloquine Hydrochloride. The reporter did not provide the seriousness criteria of the event of Homicide and its causal relationship with Mefloquine Hydrochloride. The company assessed the event of Homicide as medically significant. No further information was available. 
FDA - Adverse Event Reporting System (FAERS)

FOIA Case Report Information

Case ID: 8504150

Relevant Medical History:

Start Date

End Date

Continuing?

Medical History Product(s)

Start Date

End Date

Indications

Events

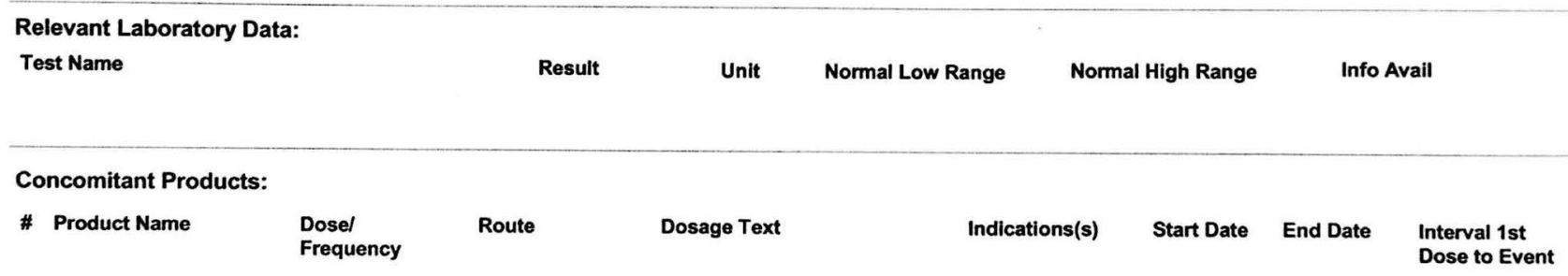

Reporter Source:

Study Report?: No

Sender Organization: ROCHE

Literature Text:

Figure 1. Adverse Drug Report filed on 29 March 2012 with the manufacturer of mefloquine (i.e. Lariam), F. Hoffmann-La Roche. The subject of this redacted ADR was Staff Sergeant Robert Bales, US Army. Initial newspaper reports suggested that he massacred 17 unarmed civilians in Afghanistan's Kandahar province, on a single night in March 2012. The subsequent military police investigation showed that the death toll was in fact 16 civilians.

to cause liver damage [1], is likely to represent an additional risk factor for his development of a severe reaction to mefloquine. This putative additional risk factor in the pathogenesis of severe and/or prolonged reactions to quinoline antimalaria drugs has not previously been highlighted, either by us or by other researchers.

\section{Conclusions}

The quinoline class of antimalaria drugs includes amodiaquine, chloroquine, mefloquine and tafenoquine. It has been known for decades that this class of drugs can precipitate unwanted neuropsychiatric effects [5]. Mefloquine appears to be the most dangerous of these drugs, since it is neurotoxic in animal models [26], and has been associated with sudden and irrational acts of extreme violence in humans [27]; Case Study Three in our lay series typifies this. The pharmacology of mefloquine is imperfectly un- 
derstood [28]. Until it is properly elucidated, we recommend that mefloquine should not be prescribed as malaria prophylaxis under any circumstances whatsoever.

Where quinoline antimalaria drugs have been given historically, and drug-induced adverse effects have occurred and have persisted, we suggest a five-point management strategy that we believe will in most cases result in rapid symptom abatement. Our suggested management strategy for treating long-lasting quinoline adverse effects is as follows.

\subsection{Stop the Quinoline Drug}

The incriminated quinoline agent should be stopped immediately, and should not ever be taken again, by that individual. If the drug-damaged individual is a traveller in a malaria-endemic zone, it will be necessary for that traveler to immediately start taking an alternative, non-quinoline antimalaria agent (e.g. doxycycline monohydrate, or atovaquone-proguanil), as malaria prophylaxis.

\subsection{Stop All Alcohol}

Alcohol should be stopped completely for a month. At the same time, all other liverdamaging drugs that are not essential to life (e.g. anabolic steroids, hormonal contraception, hormone replacement therapy, recreational drugs, antidepressants, anxiolytics and hypnotics) should be discontinued.

\subsection{Maintain Good Hydration}

Hydration should be maintained by drinking plain water, and not through drinking coffee or tea, both of which are dehydrating [1]. Non-fluoridated drinking water only (e.g. bottled spring water) should be used, since fluoride in drinking water can damage the liver [29].

\subsection{Eliminate Vitamin a from the Diet}

For one month, dietary sources of vitamin A should be eliminated. The richest food source for vitamin A is liver, but it is also found in milk, cheese, egg yolks and fish oils [30]; all these foodstuffs should be avoided. Deficiency is unlikely to result in the short or medium term, since the liver contains enough stored vitamin A to last two years [30].

\subsection{Reduce Circulating Retinoids (Optional)}

In extreme cases of quinoline-induced damage, the concentration of circulating retinoids could be lowered, under careful medical supervision. This could be achieved through phlebotomy, plasmapheresis or hirudotherapy (i.e. leech therapy) [31].

\section{Acknowledgements}

We thank Dr Remington Nevin, ex-US Army, for his helpful comments in relation to Case Study Three. We also acknowledge our late colleague Dr Andrew Herxheimer, who wrote sagely on mefloquine's adverse effects and on many related topics and would have been an enthusiastic third author of this paper, we believe, but who sadly died just 
before we conceived the idea for it.

\section{Conflict of Interests}

AC has given expert testimony in historic Court cases involving quinoline drugs, and he has advised government enquiries into the use of Lariam in soldiers.

\section{References}

[1] Croft, A.M. and Herxheimer, A. (2002) Adverse Effects of the Antimalaria Drug, Mefloquine: Due to Primary Liver Damage with Secondary Thyroid Involvement? BMC Public Health, 2, 6. https://doi.org/10.1186/1471-2458-2-6

[2] Mawson, A.R. (2013) Mefloquine Use, Psychosis, and Violence: A Retinoid Toxicity Hypothesis, Medical Science Monitor, 19, 579-583. https://doi.org/10.12659/MSM.889033

[3] Croft, A.M., Whitehouse, D.P., Cook, G.C. and Beer, M.D. (2002) Expert Opinion: Safety Evaluation of the Drugs Available to Prevent Malaria. Expert Opinion in Drug Safety, 1, 19-27. https://doi.org/10.1517/14740338.1.1.19

[4] Ball, J.W., Dains, J.E., Flynn, J.A., Solomon, B.S. and Stewart, R.W. (2015) Seidel's Physical Examination. 8th Edition, Elsevier, St Louis, Missouri.

[5] Nevin, R.L. and Croft, A.M. (2016) Psychiatric Effects of Malaria and Anti-malarial Drugs: Historical and Modern Perspectives. Malaria Journal, 15, 332. https://doi.org/10.1186/s12936-016-1391-6

[6] Landy, D. (1985) Pibloktoq (Hysteria) and Inuit Nutrition: Possible Implication of Hypervitaminosis A. Social Science and Medicine, 21, 173-185. https://doi.org/10.1016/0277-9536(85)90087-5

[7] O’Donnell, J. (2004) Polar Hysteria: An Expression of Hypervitaminosis A. American Journal of Therapeutics, 11, 507-516. https://doi.org/10.1097/01.mjt.0000123408.73790.d1

[8] Mawson, A.R., Eriator, I. and Karre, S. (2015) Stevens-Johnson Syndrome and Toxic Epidermal Necrolysis (SJS/TEN): Could Retinoids Play a Causative Role? Medical Science Monitor, 21, 133-143. https://doi.org/10.12659/MSM.891043

[9] van den Ende, E., van Gompel, A., Colebunders, R. and van den Ende, J. (1991) Mefloquine-Induced Stevens-Johnson Syndrome. The Lancet, 337, 683. https://doi.org/10.1016/0140-6736(91)92509-Z

[10] Phillips-Howard, P.A. and Buckler, W.J. (1988) Idiosyncratic Reaction Resembling Toxic Epidermal Necrolysis Caused by Chloroquine and Maloprim. British Medical Journal, 296, 1605. https://doi.org/10.1136/bmj.296.6636.1605

[11] Erickson, J.M. and Mawson, A.R. (2000) Possible Role of Endogenous Retinoid (Vitamin A) Toxicity in the Pathophysiology of Primary Biliary Cirrhosis. Journal of Theoretical Biology, 206, 47-54. https://doi.org/10.1006/jtbi.2000.2102

[12] Mawson, A.R. (2013) Retinoids, Race and the Pathogenesis of Dengue Hemorrhagic Fever. Medical Hypotheses, 81, 1069-1074. https://doi.org/10.1016/j.mehy.2013.08.004

[13] Rouve, N., Bagheri, H., Telmon, N. et al. (2011) Prescribed Drugs and Violence: A Case/ Noncase Study in the French PharmacoVigilance Database. European Journal of Clinical Pharmacology, 67, 1189-1198. https://doi.org/10.1007/s00228-011-1067-7

[14] Thomas, K.H., Martin, R.M., Potokar, J., Pirmohamed, M. and Gunnell, D. (2014) Reporting of Drug Induced Depression and Fatal and Non-Fatal Suicidal Behaviour in the UK from 1998 to 2011. BMC Pharmacology and Toxicology, 15, 54. https://doi.org/10.1186/2050-6511-15-54

[15] Toovey, S. (2009) Mefloquine Neurotoxicity: a Literature Review. Travel Medicine and Infectious Disease, 7, 2-6. https://doi.org/10.1016/j.tmaid.2008.12.004 
[16] MacLean, D.S. (2014) The Answer to the Riddle Is Me. Houghton Mifflin Harcourt, New York.

[17] Harley, N. (2014) It Was Comedy or Insanity for Me, Says Merton. The Sunday Telegraph [London], 7 September 2014, 15.

[18] Merton, P. (2014) Only When I Laugh. Ebury Press, London.

[19] Ashton, A. (2014) Nobody Was That Crazy: Documents Show Soldiers Called Robert Bales “Paranoid” Well before Killings. Tacoma News Tribune, 5 July 2014, 7.

[20] Owen, J. (2013) Lariam: History of Violence. The Independent [London], 27 September 2013, 5 .

http://www.independent.co.uk/news/uk/home-news/exclusive-the-lariam-scandal-mod-ign ored-decades-of-warnings-about-dangers-of-suicide-drug-8842496.html

[21] Rifkind, H. (2016) My Six Months of Madness (and the Drug That Helped Cause It). The Spectator [London], 26 May 2016, 26.

[22] Aronson, J.K. and Hauben, M. (2006) Anecdotes That Provide Definitive Evidence. British Medical Journal, 333, 1267-1269. https://doi.org/10.1136/bmj.39036.666389.94

[23] Herxheimer, A., Healy, D. and Menkes, D.B. (2012) Case Histories as Evidence. International Journal of Risk and Safety in Medicine, 24, 23-29.

[24] Jopp, D.S., Wozniak, D., Damarin, A.K., De Feo, M., Jung, S. and Jeswani, S. (2015) How Could Lay Perspectives on Successful Aging Complement Scientific Theory? Findings from a U.S. and a German Life-Span Sample. Gerontologist, 55, 91-106. https://doi.org/10.1093/geront/gnu059

[25] Anonymous (2015) FDA-Adverse Event Reporting System (FAERS). Adverse Event Report Filed with the Drug Manufacturer on 29 March 2012, Case ID: 8504150.

http://archive.seattleweekly.com/news/947707-129/bales-mefloquine-drug-military-nevin-b ehavior

[26] Dow, G., Bauman, R., Caridha, D., et al. (2006) Mefloquine Induces Dose-Related Neurological Effects in a Rat Model. Antimicrobial Agents and Chemotherapy, 50, 1045-1453. https://doi.org/10.1128/AAC.50.3.1045-1053.2006

[27] Croft, A.M. (2007) A Lesson Learnt: The Rise and Fall of Lariam and Halfan. Journal of the Royal Society of Medicine, 100, 170-174. https://www.ncbi.nlm.nih.gov/pmc/articles/PMC1847738/

[28] Vinetz, J.M., Clain, J., Bounkeua, V., Eastman, R.T. and Fidock, D. (2011) Chemotherapy of Malaria. In: Brunton, L.L., Chabner, B.A. and Knollmann, B.C., Eds., Goodman \& Gilman's the Pharmacological Basis of Therapeutics, 12th Edition, McGraw-Hill, London, 1383-1418.

[29] Xiong, X., Liu, J., He, W., et al. (2007) Dose-Effect Relationship between Drinking Water Fluoride Levels and Damage to Liver and Kidney Functions in Children. Environmental Research, 103, 112-116. https://doi.org/10.1016/j.envres.2006.05.008

[30] Elia, M. and Lanham-New, S.A. (2017) Nutrition. In: Kumar, P. and Clark, M., Eds., Kumar \& Clark's Clinical Medicine, 9th Edition, Elsevier Saunders, London, 183-218.

[31] Rados, C. (2004) Beyond Bloodletting: FDA Gives Leeches a Medical Makeover. FDA Consumer, 38, 9. 
Submit or recommend next manuscript to SCIRP and we will provide best service for you:

Accepting pre-submission inquiries through Email, Facebook, LinkedIn, Twitter, etc. A wide selection of journals (inclusive of 9 subjects, more than 200 journals) Providing 24-hour high-quality service

User-friendly online submission system

Fair and swift peer-review system

Efficient typesetting and proofreading procedure

Display of the result of downloads and visits, as well as the number of cited articles Maximum dissemination of your research work

Submit your manuscript at: http://papersubmission.scirp.org/

Or contact ojas@scirp.org 